\title{
Acceleration and deceleration of sexual maturation by social cues in a tropical rodent Zygodontomys brevicauda
}

\author{
T. Pierson ${ }^{*}$ and P. D. Heideman ${ }^{\dagger}$ \\ Institute of Reproductive Biology and Department of Zoology, University of Texas, Austin, TX 78712, USA
}

\begin{abstract}
The effects of social cues from adult conspecifics on the rate of sexual maturity were studied in a tropical rodent, the cane mouse (Zygodontomys brevicauda), in the laboratory. Several aspects of the biology of this species have suggested that it might be atypical in that young females may not accelerate or decelerate their rate of reproductive development in response to social cues. This hypothesis was tested by housing 16-day-old females with an adult male, an adult female, or alone, and reproductive development was assessed periodically, beginning when the mice were 20 days old. Young females paired with males underwent more uterine growth and matured markedly earlier than did isolated controls. Young females paired with adult females exhibited less uterine growth than did isolated controls. Thus, social cues both accelerate and decelerate reproductive development in females of this species, and the hypothesis that social cues have no effect on reproductive development in young females was rejected. The evolutionary conditions that favour unresponsiveness of young females to social cues appear to be restrictive, and may be rare in mammals.
\end{abstract}

\section{Introduction}

An important component of the strategy an individual mammal uses to maximize its reproductive fitness is the timing of reproductive maturity (Cole, 1954; Lewontin, 1965). Every species must have some theoretical minimum age of reproductive maturity that may be modified by environmental conditions. The age at which an individual actually matures depends upon a variety of nutritional, social and other factors (reviewed by Bronson, 1989). Under permissive nutritional conditions in the laboratory, reproductive maturity can be delayed or accelerated in many species by social cues from conspecifics. In many species, exposure of individuals to adults of the opposite sex accelerates sexual maturity while exposure to adults of the same sex delays puberty (reviewed by Drickamer, 1986; Vandenbergh, 1989; Bronson, 1989; Sawrey and Dewsbury, 1991). A number of studies have provided evidence that these social cues can also play significant roles in the regulation of reproductive maturity in natural populations (Massey and Vandenbergh, 1980, 1981; Heske and Nelson, 1984; Coppola, 1986; Coppola and Vandenbergh, 1987; Vandenberg, 1987). The effects have been reported in so many species (Bronson, 1989) that they appear to be the norm among rodents, and are at least common in other mammalian orders.

This study was prompted by laboratory and field observations suggesting that female cane mice, Zygodontomys brevicauda, fail to accelerate or decelerate reproductive maturity in response to social cues. In the wild on the Llanos of

\footnotetext{
*Present address: Department of Cell Biology, Baylor College of Medicine, Houston, TX 77030, USA.

†Present address: Department of Biology, College of William and Mary, Williamsburg, VA 23187, USA.

Revised manuscript received 30 June 1994
}

Venezuela, reproduction is nonseasonal in this species (Vivas, 1984; O'Connell, 1989). The Llanos has severe wet and dry seasons, and August (1984) suggested that the seasons are so extreme that there may not be an optimum season for reproduction in cane mice. Laboratory data demonstrate that maturity in $Z$. brevicauda is not delayed or accelerated when they are exposed to either long or short photoperiods (Heideman and Bronson, 1990). Experimental treatments that can unmask reproductive photoresponsiveness in other rodents fail to do so in cane mice (Bronson and Heideman, 1992). Laboratory-bred female cane mice can become sexually mature very early, as 21-day-old, newly weaned females can become pregnant within days of pairing with a male (Voss et al., 1992). Characteristics of oestrous cycles were not affected by the presence of a male on the other side of a wire partition (Voss et al., 1992). All of these observations suggested that cane mice might ignore external cues, both seasonal and social, during reproductive development, resulting in rapid maturation limited only by nutritional status. The experiments in this paper test the hypothesis that social cues do not affect the rate of reproductive development in female $Z$. brevicauda.

\section{Materials and Methods}

Two experiments were conducted. In both, the animals used were approximately the eighth laboratory generation of an outbred colony originally established by R. S. Voss at the American Museum of Natural History, New York, from a wild stock obtained at Hato el Frio, Estado Apure, Venezuela $\left(7^{\circ} \mathrm{N}\right.$, $68^{\circ} 44^{\prime} \mathrm{E}$; elevation approximately $60 \mathrm{~m}$; Voss, 1991; Voss et al., 1992). All animals were maintained at $24 \pm 1^{\circ} \mathrm{C}$. Animals used in the experiments were kept under the same light schedule as 
Table 1. Body weight (mean \pm SEM) and reproductive characteristics of female cane mice (Zygodontomys brevicauda) housed with adult males or in isolation

\begin{tabular}{|c|c|c|c|}
\hline Characteristic & Isolate & Male-paired & Probability \\
\hline \multicolumn{4}{|l|}{20 days old } \\
\hline Body weight & $2.3 .7 \pm 0.8$ & $22.6 \pm 0.1$ & NS \\
\hline Uterine weight & $19.1 \pm 2.0$ & $52.8 \pm 8.6$ & $<0.01$ \\
\hline $\begin{array}{l}\text { Percentage with large, tertiary } \\
\text { follicles or corpora lutea }\end{array}$ & 0 & 10 & NS \\
\hline \multicolumn{4}{|l|}{30 days old } \\
\hline Body weight & $28.4 \pm 1.2$ & $32.2 \pm 0.9$ & $<0.05$ \\
\hline Uterine weight & $47.0 \pm 8.2$ & Not applicable $\mathrm{a}^{\mathrm{a}}$ & Not applicable ${ }^{a}$ \\
\hline $\begin{array}{l}\text { Percentage with large, tertiary } \\
\text { follicles or corpora lutea }\end{array}$ & 10 & 100 & $<0.05$ \\
\hline
\end{tabular}

${ }^{\mathrm{a}}$ All of the females at this stage of treatment carried fetuses at the time of autopsy.

NS: not significant.

the breeding colony ( $13 \mathrm{~h}$ light: $11 \mathrm{~h}$ dark with lights on at 08:00 h). There is no evidence that photoperiod affects reproductive status in this species (Heideman and Bronson, 1990; Bronson and Heideman, 1992). Individuals and pairs were housed in polyethylene cages measuring $29 \mathrm{~cm} \times 18 \mathrm{~cm} \times$ $12 \mathrm{~cm}$ containing pine shavings to a depth of approximately $3 \mathrm{~cm}$. All were given food (Purina Formulab 5008, RalstonPurina Co., St Louis, MO) and water ad libitum.

In this species, vaginal opening and other external reproductive characteristics are poor indicators of reproductive maturity; these mice have typical oestrous cycles of about 4-7 days (Voss, 1991; Voss et al,, 1992). Uterine weight and the ovarian condition were therefore used as indicators of reproductive development. Because $Z$. brevicauda ovulate spontaneously (Voss et al., 1992), the presence of corpora lutea or large tertiary follicles (diameter $>2 \mathrm{~mm}$, similar in size to corpora lutea) was considered to be evidence of reproductive maturity. Uterine weights were measured immediately after uteri were removed, opened and drained of any fluid, and blotted gently on a paper towel. Test females were housed directly with stimulus animals rather than separated using a barrier to include the effects of tactile as well as other potential cues (Bronson and Maruniak, 1975; Drickamer, 1977; Carter et al., 1987). Individuals were weaned $16 \pm 1$ days after birth and immediately placed into their respective treatment group. Treatment groups in each experiment were matched for bodyweight, because body. weight may affect reproductive development and responses to social cues in rodents (Bronson and Desjardins, 1974; Bronson and Macmillan, 1983). Changes in bodyweight were recorded to test for the effects of treatment on somatic growth. Body and uterine weights were compared across treatments (male-paired versus isolated groups and femalepaired versus isolated groups) and ages using a separate two-way analysis of variance for each experiment, and were compared at particular ages using Student's $f$ test.

\section{Experiment 1}

This experiment examined the effects of unfamiliar adult males on female reproductive development. Eight groups of
9-10 females aged $16 \pm 1$ days and weighing $16-24 \mathrm{~g}$ were formed and siblings were assigned to different treatment groups. Young females in four of the groups were housed alone (isolates), and females in the other four groups were paired with adult males (male-paired). One group of isolates and one group of male-paired females were autopsied at 20,30, 40 and 55 days of age.

\section{Experiment 2}

Expt 2 was conducted simultaneously with Expt 1 and shared the mice in the isolated groups that were autopsied at 30, 40 and 55 days of age in Expt 1. In Expt 2, the effect of unfamiliar adult females on female reproductive development was examined. Groups of 9-10 females aged $16 \pm 1$ days and weighing 16-24 $\mathrm{g}$ were formed and siblings were assigned to different treatment groups. Young females in four of the groups were housed alone (isolates), and females in the other four groups were paired with adult females (female-paired). Isolate and female-paired female groups were compared at 30 , 40,55 and 70 days of age.

\section{Results}

\section{Experiment 1}

Uterine development in weanling females paired with adult males was accelerated significantly compared with that of isolated females. At 20 days of age, after $4 \pm 1$ days of exposure to a male, uterine weights were more than double those of isolated females (Table 1; $P<0.01$ ). Isolated females required an additional 10 days to approach the uterine weights of male-paired females (Table 1 ). At 30 days of age, the ovaries of only one of ten isolated females had corpora lutea or large tertiary follicles, while those of all 30-day-old male-paired females had corpora lutea or large tertiary follicles. Eight of ten male-paired females were pregnant at 30 days of age, as were eight of ten male-paired females at 40 days of age. Data on the 55 -day-old male-paired females, $60 \%$ of which delivered pups at 46 days of age, were used to determine the age of 
Table 2. The effect of both age and treatment on the uterine size (mean \pm SEM) of young female cane mice

(Zygodontomys brevicauda) comparing isolated and female-paired treatments

\begin{tabular}{|c|c|c|c|}
\hline Characteristic & Isolate & Female-paired & Probability \\
\hline \multicolumn{4}{|l|}{30 days old } \\
\hline Body weight & $28.4 \pm 1.2$ & $31.9 \pm 4.2$ & 0.06 \\
\hline Uterine weight & $47.0 \pm 8.2$ & $44.2 \pm 9.3$ & NS \\
\hline $\begin{array}{l}\text { Percentage with large, tertiary } \\
\text { follicles or corpora lutea }\end{array}$ & 10 & 0 & \\
\hline \multicolumn{4}{|l|}{40 days old } \\
\hline Body weight & $37.5 \pm 5.6$ & $43.0 \pm 5.1$ & 0.05 \\
\hline Uterine weight & $57.7 \pm 7.9$ & $34.9 \pm 7.4$ & 0.05 \\
\hline $\begin{array}{l}\text { Percentage with large, tertiary } \\
\text { follicles or corpora lutea }\end{array}$ & 40 & 10 & \\
\hline \multicolumn{4}{|l|}{55 days old } \\
\hline Body weight & $37.7 \pm 10.7$ & $41.7 \pm 6.4$ & NS \\
\hline Uterine weight & $74.7 \pm 8.4$ & $59.5 \pm 13.4$ & NS \\
\hline $\begin{array}{l}\text { Percentage with large, tertiary } \\
\text { follicles or corpora lutea }\end{array}$ & 30 & 30 & \\
\hline \multicolumn{4}{|l|}{70 days old } \\
\hline Body weight & $46.4 \pm 5.7$ & $43.9 \pm 6.4$ & NS \\
\hline Uterine weight & $83.6 \pm 9.2$ & $53.3 \pm 8.0$ & 0.03 \\
\hline $\begin{array}{l}\text { Percentage with large, tertiary } \\
\text { follicles or corpora lutea }\end{array}$ & 40 & 0 & \\
\hline
\end{tabular}

NS: not significant.

fertilization. Cane mice have a mean gestation period of 25 days (Voss et al., 1992), indicating that most females were impregnated, and therefore reproductively mature, between about 19 and 23 days of age. Isolated females of this age had immature uteri and small ovaries without large tertiary follicles or corpora lutea. Overall, body weight was similar in the two groups $(F=2.19 ; P>0.10)$. Results for treatments lasting 40 and 55 days are not presented in Table 1 because almost all male-paired females were pregnant with advanced embryos.

\section{Experiment 2}

The uterine development of young females paired with adult females was significantly inhibited $(F=7.57 ; P<0.01$; Table 2$)$. Uterine weight also increased with age $(F=3.80 ; P<0.05$; Table 2), and the interaction between treatment and age was not significant $(F=0.73 ; P>0.50)$. Female-paired young had consistently lower uterine weights than those of isolated mice (Table 2). The greatest differences between the two treatment groups occurred in the 40-day-old and 70-day-old females $(P<0.05 ; P<0.03$, respectively). In both groups of young females there were few large tertiary follicles and corpora lutea, but the lower frequency in female-paired young females was not statistically significant $(P>0.10$; Table 2$)$. There was a trend towards lower body weight in isolated females $(F=3.16$; $P=0.08$ ).

\section{Discussion}

Social cues clearly affect the timing of reproductive development in female cane mice in the laboratory. Adult males stimulated uterine growth and ovulation while adult females inhibited uterine growth in young females. The higher body weight of female-paired females relative to isolated females suggests a possible trade-off between reproductive maturity and somatic growth, but this difference was not observed in older females. The effect of an adult male was potent, as females were capable of conceiving within days of exposure to a male beginning at 16 days of age, while isolated females retained reproductive tracts that were juvenile in appearance for an additional 10-20 days. Clearly, isolated cane mice do not mature at their maximum potential rate. Combined with the evidence of inhibitory effects of adult females on uterine development, these results demonstrate the potential for considerable flexibility in the rate of reproductive maturation.

Voss et al. (1992) reported that female cane mice become reproductively mature extremely rapidly in the laboratory. Our results indicate that this rapid maturation is conditional upon male exposure and the absence of adult females. Reproductive maturation in young, isolated females occurs at an intermediate rate. Rather than being insensitive to social cues, female cane mice are very sensitive to these cues, at least in the laboratory. In the wild, rates of reproductive development could vary dramatically both temporally and spatially according to local social conditions in this species. The ability to delay or accelerate reproductive maturity in response to social cues may be particularly important when populations reach high densities.

A number of hypotheses have been proposed to explain the evolution and maintenance of reproductive responses to social cues. The acceleration and deceleration of reproductive maturity in response to social cues can be interpreted as a mechanism to synchronize seasonal reproduction (Bronson, 1985), as a mechanism to protect a female from sexual maturation before dispersal (Bronson, 1979) or as adaptive responses of young individuals to local population density and 
other social conditions that favour or disfavour early reproduction (Rogers and Beauchamp, 1976; Coppola, 1986; Drickamer, 1986). Actual testing of the individual hypotheses for individual species, such as cane mice, requires additional information from the laboratory and the field. The important point here is that one or more of these hypotheses could apply to virtually any species of mammal. Thus, these hypotheses provide a theoretical framework that may account for the large number of species in which social cues have been shown to modify reproductive development (reviewed by Drickamer, 1986; Vandenbergh, 1989; Bronson, 1989). Our study was prompted by observations that suggested that the cane mouse might be an exception to this generality. However, reproductive development in this aseasonally reproducing, reproductively precocial, tropical species can be affected markedly by social cues. This finding supports the hypothesis that social cues play a fundamental role in the regulation of reproductive development of mammals, and suggests that species in which social cues are unimportant may be extremely unusual.

We do not know of any mammalian species in which social cues from adult conspecifics have been demonstrated not to have a role in regulating rates of reproductive maturation. This may be related simply to the difficulty of demonstrating unresponsiveness and then publishing the negative data, but it may also reflect the ubiquity of the phenomena among mammals. It is possible that conditions that favour the evolution of a tendency in young females to ignore social cues in reproductive development are uncommon in mammals. There are five conditions that would favour individuals that ignored social cues: synchronizing reproduction with other individuals socially provides no increase in fitness (for example, if reproduction is strictly aseasonal and asynchronous, or if environmental cues such as the photoperiod synchronize reproduction); females have no difficulty encountering potential mates, and hence gain no advantage from delaying maturation until contact with a mate; insemination is the sole contribution required for successful reproduction (i.e. other resources contributed by a male, including male parental care, are unnecessary); female reproductive success is not increased by suppressing reproduction in the presence of adult conspecifics (for example, there is no harassment by older females, nor are young females more likely to lose any competition for scarce resources); and inbreeding from father-daughter matings is either unlikely or is not disadvantageous. Unless all of these conditions are met, natural selection might favour the use of social cues to modify the timing of reproductive maturity. Previous work on cane mice supported the first condition and suggested that the second and third were likely as well, but the last two conditions may not hold for cane mice. Species for which all of these conditions are met may be rare. However, we suggest that a search for species in which social cues clearly do not affect reproductive development would allow better characterization of the potential selective advantages of these phenomena, and would improve our understanding of the conditions favouring their evolution and retention.

The authors thank F. H. Bronson for helpful suggestions on an earlier draft of the manuscript, and S. Beckwith, K. Hoskins and R. Vaughn for their assistance on this project. This study was supported by NIH grant HD 24177 .

\section{References}

August PV (1984) Population ecology of small mammals in llanos of Venezuela. In Special Publications of the Museum of Texas Tech University Vol. 22 pp 71-104. Texas Tech University

Bronson FH (1979) The reproductive ecology of the house mouse Quarterly Review of Biology 54 265-299

Bronson FH (1985) Mammalian reproduction: an ecological perspective Biology of Reproduction 32 1-26

Bronson FH (1989) Mammalian Reproductive Biology. The University of Chicago Press, Chicago

Bronson FH and Desjardins C (1974) Circulating concentrations of FSH, LH, estradiol and progesterone associated with acute, male-induced puberty in female mice Endocrinology 94 1658-1668

Bronson FH and Heideman PD (1992) Lack of reproductive photoresponsiveness and correlative failure to respond to melatonin in a tropical rodent, the cane mouse Biology of Reproduction 46 246-250

Bronson FH and Macmillan B (1983) Hormonal response to primer pheromones. In Pheromones and Reproduction in Mammals pp 175-197 Ed. IG Vandenbergh. Academic Press, New York

Bronson FH and Maruniak JA (1975) Male-induced puberty in female mice: evidence for a synergistic action of social cues Biology of Reproduction 13 94-98

Carter CS, Witt DM, Schneider J, Harris ZL and Volkening D (1987) Male stimuli are necessary for female sexual behavior and uterine growth in prairie voles (Microtus ochrogaster) Hormones and Behavior 21 74-82

Cole LC (1954) The population consequence of life history phenomena Quarterly Review of Biology 29 103-137

Coppola DM (1986) The puberty delaying pheromone of the house mouse: field data and a new evolutionary perspective. In Chemical Signals in Vertebrates Vol. 4 pp 457-461 Eds D Duvall, D Muller-Schwarze and RM Silverstein. Plenum Press, New York

Coppola DM and Vandenbergh JG (1987) Induction of a puberty-regulating chemosignal in wild mouse populations Journal of Mammalogy 68 86-91

Drickamer LC (1977) Delay of sexual maturation in female house mice by exposure to grouped females or urine from grouped females Journal of Reproduction and Fertility $\mathbf{5 1} 77-81$

Drickamer LC (1986) Puberty-influencing chemosignals in house mice: ecological and evolutionary considerations. In Chemical Signals in Vertebrates Vol. 4 pp 441-455 Eds D Duvall, D Muller-Schwarze and RM Silverstein. Plenum Press, New York

Heideman PD and Bronson FH (1990) Photoperiod, melatonin secretion, and sexual maturation in a tropical rodent Biology of Reproduction 43 745-750

Heske EJ and Nelson RJ (1984) Pregnancy interruption in Microtus ochrogaster: laboratory artifact or field phenomenon? Biology of Reproduction 31 97-103

Lewontin RC (1965) Selection for colonizing ability. In The Genetics of Colonizing Species pp 79-94 Eds HG Baker and GL Stebbins. Academic Press, New York

Massey A and Vandenbergh JG (1980) Puberty delay by a urinary cue from female house mice in feral populations Science 209 821-822

Massey A and Vandenbergh JG (1981) Puberty acceleration by a urinary cue from male mice in feral populations Biology of Reproduction 24 523-527

O'Connell MA (1989) Population dynamics of neotropical small mammals in seasonal habitats Journal of Mammalogy 70 532-548

Rogers JG and Beauchamp GK (1976) Some ecological implications of primer chemical stimuli in rodents. In Mammalian Olfaction, Reproductive Processes and Behavior pp 181-195 Ed. R Doty. Academic Press, New York

Sawrey DK and Dewsbury DA (1991) Males accelerate reproductive development in female montane voles Journal of Mammalogy 72 343--346

Vandenbergh JG (1987) Population dynamics of mice American Zoologist 27 891-898

Vandenbergh JG (1989) Coordination of social signals and ovarian function during sexual development Journal of Animal Science 67 184I-1847

Vivas AM (1984) Ecologia de poblaciones de los roedores de los llanos de Guarico Trabajo de Ascenso, Universidad Simon Bolivar

Voss RS (199I) An introduction to the neotropical muroid rodent genus Zygodontomys Bulletin of the American Museum of Natural History 210 1-113

Voss RS, Heideman PD, Mayer VL and Donnelly TM (1992) Husbandry, reproduction and postnatal development of the neotropical muroid rodent Zygodontomys brevicauda Laboratory Animals 26 38-46 